\title{
BRINGING CONTEXT AND STRUCTURE BACK INTO SITUATED LEARNING
}

\author{
Jasper J. Hotho, Department of Strategic Management and Globalization,
} Copenhagen Business School, Denmark ${ }^{1}$

Ayse Saka-Helmhout, Surrey Business School, University of Surrey, Guildford, UK

Florian Becker-Ritterspach, Faculty of Management Technology, German University in Cairo, Egypt

\footnotetext{
${ }^{1}$ Corresponding author: Jasper J. Hotho, Department of Strategic Management and Globalization,
} Copenhagen Business School, Kilevej 14, DK-2000, Frederiksberg, Denmark. Email: jjh.smg@cbs.dk. 


\title{
BRINGING CONTEXT AND STRUCTURE BACK INTO
}

\section{SITUATED LEARNING}

\begin{abstract}
Practice-based studies have progressed thinking in the knowledge, learning and innovation field by emphasizing the continual negotiation of social structures and meaning through participation. Yet only a few contributions discuss how participation and learning are affected by broader structures. This is an inconsistency in the understanding of 'situated' learning where learning through participation is restricted to the immediate community involved in a social activity. We aim to address this inconsistency by investigating the effects of the interplay between institutional and organizational structures on patterns of participation and, in turn, learning outcomes. We develop a framework of situated learning in MNEs, and explore its value through a comparative case study of the introduction of new practices in four subsidiaries of two MNEs in two contrasting national institutional systems. Our case findings suggest that while the interplay between institutional context and organizational structure indeed matters, it does not determine collective participation and situated learning as actors can actively create solutions when structural conditions and institutional demands are less aligned.
\end{abstract}

\section{Keywords}

situated learning, practice-based studies, multinational enterprises, communities of practice, institutions, context, structure 
'Our conviction is that the analytical potential of a situated understanding of learning will be fulfilled only when studies of learning in organizations more fully appreciate and demonstrate how learning processes are inextricably implicated in the social reproduction of wider institutional structures.' (Contu and Willmott, 2003: 294)

\section{INTRODUCTION}

Recent work in practice-based studies (PBS hereafter) shows a growing interest in the role of societal institutions (e.g., Gherardi and Perrotta, 2011; Lounsbury, 2008; Lounsbury and Crumley, 2007). While still modest, this development is important because it signals a shift in focus from the immediate organizational context in which knowing, learning and practice takes place, to how situated action is affected by wider societal influences and differs across contexts. Gherardi and Perrotta (2011), for instance, draw on insights from organizational institutionalism to argue and illustrate that new practices not only originate from within communities of practitioners, but may also be instigated and affected by exogenous forces, such as public discourse and changed legislation. Thus, their study not only highlights that societal institutions often have a direct bearing on practice, but also illustrates the important point that attention to societal structures brings about a richer, more holistic approach to practice research (Lounsbury, 2008).

In this paper, we aim to add to this emergent line of study by highlighting a second set of influences through which institutional structures affect situated learning and practice, namely, through their combined influence with organizational structure. Specifically, combining insights from PBS emphasizing context and practice (Brown and Duguid, 2001; Thompson, 2005) and comparative institutionalism focusing on national institutional structures (Hall and Soskice, 2001; Whitley, 1999), we argue that institutionally structured differences in communities of practice (CoPs), and the relations between them, may interact with formal organizational structures to produce different participation patterns and learning outcomes. This complements recent practicebased studies by highlighting that institutions not only affect practice directly, such as through regulations, norms and broader cultural frameworks (e.g. Gherardi and Perrotta, 2011; Lounsbury, 2008; Mørk et al., 2010), but also indirectly, because their interaction with formal structures 
shapes how participation and learning plays out within organizations.

This point is important, because it may contribute to a better understanding of the variety in situated learning and practice between organizations and institutional settings. As Roberts (2006) indicates, as social configurations, communities of practice will inherently reflect the broader institutions of the context in which they are situated. That is, the contexts in which groups of practitioners are embedded have an impact on the extent to which these groups are cohesive and cooperate with one another and, in turn, how they drive learning and knowledge formation in organizations. While the notion of context was central in originating research into situated learning (Brown and Duguid, 1991; Lave and Wenger, 1991), this emphasis was lost in later applications (Amin and Roberts, 2008; Gherardi and Perrotta, 2011). As a result, we still have only a limited understanding of whether and how situated learning and practice differ across contexts and what the implications are for the transfer and acquisition of knowledge across them (Yakhlef, 2010).

This is particularly problematic for our understanding of situated learning and knowledge processes within organizations whose units are dispersed across different national contexts, such as multinational enterprises (MNEs). MNEs rely heavily on the ability to transfer and recombine knowledge across national boundaries (Kogut and Zander, 1993). Furthermore, the notion of alternative MNE organizational structures suggest that even in similar national contexts, knowledge integration may proceed in different ways. This implies that to understand situated learning in organizations that rest on knowledge transfer across contexts and communities, we need to closely consider the interplay between organizational and institutional structures.

We, therefore, seek to contribute to the practice-based literature by considering how situated learning plays out in contexts that are defined by different formal structures. Specifically, we explore the joint impact of organizational and institutional structures on collective participation in subsidiaries. We do this, first, by developing a contingency framework in which we contextualize the situated learning that takes place in subsidiaries. We subsequently explore this framework via a comparative study of the integration of new practices in four subsidiaries of two rival MNEs in the chemical industry.

Our findings suggest that while the interaction between institutional and organizational 
structures indeed matters, it does not determine collective participation. When the institutional environment and the MNE coordination structure are less aligned, actors have various alternative means at their disposal, such as participative leadership and employment relations, to accommodate host institutional expectations and promote participation. This insight is a useful step forward to understanding situated learning in context, especially within the units of large multinational organizations, and allows us to make useful theoretical inferences about the extent to which situated learning is conditioned by social structures.

In the sections below, we first introduce the situated learning literature, and highlight the inattentiveness to how social structures at different levels interact in their influence on collective participation and situated learning. We subsequently draw on insights from comparative institutionalism and situated learning to develop a framework of situated learning in MNEs. In the subsequent sections, we elaborate on our methods, and present the findings of our case studies. We then discuss our findings in the light of the proposed framework. In the final section, we discuss the conclusions that can be drawn from our study, and indicate several potential paths for future research.

\section{LEARNING IN THE SITUATED LEARNING LITERATURE}

The broad label of PBS covers a wide range of related approaches (Corradi et al., 2010; Nicolini et al., 2003). These include perspectives such as ‘communities of practice’ (Brown and Duguid 1991; Lave and Wenger 1991), 'knowing in practice’ (Amin and Roberts, 2008; Gherardi, 2000; Orlikowski, 2002), cultural learning (Cook and Yanow 1993), work-based learning (Raelin, 1997) and social learning perspectives (Elkjær, 2003). In spite of important differences among these approaches (Corradi et al., 2010; Nicolini et al., 2003), they share a radical critique of cognitive learning perspectives (Handley et al., 2006). Learning and knowing are seen as social processes that are based on mutual engagement in activities and situated in a wider community. Learning is therefore seen to manifest itself in collectively shared practices and identities, rather than in individual cognitive capacities or organizational repositories of knowledge (Corradi et al., 2010; Gherardi, 2006; Geiger, 2009; Handley et al., 2006; Wenger, 1998). 
While more and more contributions in organization studies draw on PBS to understand organizational learning and knowledge generation (Amin and Roberts, 2008; Corradi et al., 2010), scholars increasingly challenge the usefulness of seeing situated learning as embedded in communities that are homogeneous and cohesive (e.g., Handley et al., 2006; Lindkvist, 2005; Macpherson and Clark, 2009; Roberts, 2006). Instead, more recent perspectives highlight the divisions within and links across organizations that are created by practice and structure (see, e.g., Brown and Duguid, 2001; Macpherson and Clark 2009; Mørk et al., 2008; Thompson, 2005). In this view, organizations host communities with fundamentally different practices rooted in the organizational division of labour. Although practice creates epistemic barriers for knowledge flow across different communities that constitute complex organizations, organizational coordination mechanisms can facilitate the integration of different communities (Brown and Duguid, 2001). This gives organizations an advantage over markets in "dynamically coordinating the knowledge produced by these communities” (Brown and Duguid, 2001: 199).

\section{Situated learning: Bringing context back in}

This more differentiated view of organizations and communities helps bring PBS closer to the heterogeneous reality of contemporary work spaces. In particular, recent views have come to recognize and highlight the complexity of the internal social context in which practice takes place. For instance, recent contributions not only highlight that individuals often participate in multiple communities (Handley et al., 2006), but also draw attention to the tensions and power relations within communities, such as between novices and more experienced practitioners (Handley et al., 2006; Macpherson and Clark, 2009; Mørk et al., 2010). But while PBS is often argued to emphasize socio-cultural dynamics (Handley et al., 2006), in practice, PBS research rarely explicitly considers social structures beyond communal or organizational boundaries (Mørk et al., 2008). Brown and Duguid (2001) acknowledge that a firm’s knowledge base partially draws on broader institutional structures, but exactly how these institutional structures affect situated learning and knowledge processes, and how they interact with formal organizational structures (Nicolini, Mengis and Swan, forthcoming; Roberts, 2006), has received little attention. Exceptions aside (e.g., Gherardi and Perrotta, 2011; Hong et al., 2006), the influence of broader institutional 
effects on situated learning still seems largely unrecognized and underplayed. As a result, we have little understanding of how social learning takes place in situ, such as how the epistemic boundaries between different communities are conditioned by wider formal structures, and the implications of this for situated learning processes.

This is problematic, not only because sensitivity to context makes organizational theories more robust (e.g., Whetten, 2009), but also because many of the most knowledge-intensive contemporary organizations operate across contexts with contrasting institutional structures (Dunning, 1998). The lack of context sensitivity in situated learning is therefore particularly problematic for our understanding of situated learning in MNEs, as it implies difficulties to account for variation across units in different contexts. To address this gap we build on recent interest in PBS in the impact of structure on learning (e.g., Brown and Duguid, 2001; Gherardi and Perrotta, 2011; Thompson, 2005), and systematically explore how organizational and institutional structures interact to impact collective participation and learning in organizations. Hence, our work addresses calls in the situated learning literature for a better understanding of how different structures influence collective participation (Roberts, 2006).

\section{CONTEXTUALIZING SITUATED LEARNING IN MNEs: AN}

\section{EXPLORATIVE FRAMEWORK}

Practice-based studies increasingly recognize that learning may be conditioned by both organizational and institutional structures (Brown and Duguid, 2001; Gherardi and Perrotta, 2011; Hong et al., 2006; Thompson, 2005). Nonetheless, the interplay between these structures has neither been systematically theorized nor empirically explored. While we see this as a missed opportunity to understand learning patterns in any kind of complex organization, it is particularly problematic in the case of MNEs that are not only coordinated in different ways (Bartlett and Ghoshal, 1989; Ghoshal and Nohria, 1993) but also operate in different institutional contexts. Therefore, in the following sections, we seek to build a contextualized framework of situated learning in MNEs that combines key insights from situated learning and comparative institutionalism. 
We draw on insights from comparative institutionalism rather than, for instance, organizational institutionalism (see e.g. Gherardi and Perrotta, 2011; Lounsbury, 2008), because comparative institutionalism is explicitly concerned with how societal institutions affect economic organization (Morgan et al., 2010), such as the relations and divisions between socio-professional groups (e.g. Hall and Soskice, 2001; Whitley, 2007). We, therefore, believe that insights from comparative institutionalism are particularly useful for understanding how both the epistemic boundaries of different communities of practice and the relations between them are institutionally structured, and how this might encourage differences in situated learning between national contexts.

\section{MNEs as constellations of communities-of-practice in contrasting contexts}

We see MNEs as constellations of communities-of-practice (Nicolini and Gherardi, 2002; Wenger, 2000) that are spread out over geographically dispersed sub-units. In line with the situated learning perspective, we see learning as based on active participation in everyday practice and manifested in collectively shared practices. Specifically, in MNEs, organizational units face the ongoing task of having to integrate practices that are transferred from other units in the network, such as headquarters. This mode of learning implies that local constellations of communities of practice are asked to integrate these practices into their extant portfolio of practices. This suggests that, if integrated successfully, one can observe a change in the portfolio of practices.

We also expect that the learning outcomes of subsidiaries—-that is, the observed change in their portfolio of practices-will differ depending on the participation patterns with regard to the integration of the transferred practice. Here, following Brown and Duguid (2001), we see organizational structures as a key condition enabling and constraining active participation. We concur with Brown and Duguid (2001) that where intra-organizational divisions exist, organizational coordination assumes a key role in bridging them. These may involve, for example, the creation of boundary objects such as shared documents, tools, business processes, objectives and schedules (Brown and Duguid, 2001; Nicolini, Mengis and Swan, forthcoming).

Finally, drawing on comparative institutionalism (e.g., Hall and Soskice, 2001; Whitley, 1999; 2007), we expect that the epistemic barriers within MNE units are influenced by the 
institutional contexts of these units. Brown and Duguid (2001) argue that organizational structures have a formative influence on the epistemic barriers within organizations and, hence, on how working life is lived, how work is done, and how working identities are created. We argue that institutional structures, such as the education and industrial relations systems (Morgan et al., 2010), have a similar bearing on epistemic boundaries and bridges within organizations because they create differences in work identities and the relations between socio-professional groups (Delmestri and Walgenbach, 2005; Whitley, 2007). We therefore expect that within MNE units, both communities of practice and the relations between them will reflect the wider social structures or national institutions in which the unit is situated. Below, we draw on the polar distinction between liberal market economies (LMEs) and coordinated market economies (CMEs; Hall and Soskice, 2001) to explore how participation patterns and learning outcomes are shaped differently by institutional structures in their interaction with MNE organizational structures.

\section{Contextualizing situated learning in multinationals}

A central notion in comparative institutionalism is that the type of coordination among economic actors is a key factor distinguishing alternative types of institutional environments (Hall and Soskice, 2001; Whitley, 1999). In CMEs, the coordination of economic activity rests strongly on non-market modes of coordination among economic actors, such as between employers and employees (Hall and Gingerich, 2009; Hall and Soskice, 2001). In such economies, privileging the notion of Gemeinschaft (Tönnies, 1912), or a stakeholder- and network-based business system (Harvey and Maclean, 2010), the institutional environment encourages and facilitates information sharing and collaboration, and relations between economic actors tend to be relatively cooperative and enduring. In Germany, for instance, the dual educational system is jointly governed by professional organizations, employer associations, and trade unions, and combines on-the-jobtraining with state-regulated vocational and general training (Giardini et al., 2005). This system produces committed workers who are competent in dealing with organizational problems across skill boundaries. Such competences encourage authority sharing, and also create relatively longterm career opportunities for workers within firms (Whitley, 2007). Taken together, the delegated authority and vertical mobility in German firms contributes to a shared technical craft orientation 
and identity (Delmestri and Walgenbach, 2005; Sorge, 1995) which encourages and supports cooperation and knowledge sharing between different CoPs.

By contrast, in LMEs, coordination between economic actors primarily takes place through hierarchies and market relations (Hall and Soskice, 2001). Such relations are typically more arms' length and adversarial, with extensive unilateral control by management and strong management-worker separation (Hall and Soskice, 2001; Whitley, 1999). This is partially because the institutional context of LMEs does not foster or encourage the type of cooperative and trustworthy relations found in CMEs. Rather, in LMEs, different spheres with different actors remain relatively compartmentalized, and relations between them are more transactional. Promoting shareholder value ethos takes precedence and the notion of Gesellschaft (Tönnies, 1912), in which individuals come together mostly to serve their own interests, is privileged. For instance, in the UK education system, practical and academic training are highly separated. This encourages vastly different socio-professional identities and sharp divides within British firms. In addition, contrary to CMEs, the influence of employee interests on decision-making is not ensured through collective arrangements. Rather, it is dependent on employee relations at the firm level, such as employee information and consultation practices. As a result, there tends to be sharper divides between different CoPs and constellations of CoPs tend to be less cohesive. Therefore, in LMEs, participation in the introduction and development of new practices and capabilities often tends to be restricted to the managerial hierarchy (e.g. Whitley, 2007).

The above suggests that MNE subsidiaries in LMEs generally face higher internal divisions or epistemic barriers than subsidiaries in CMEs. It also suggests that subsidiaries in LMEs may benefit more from central coordination to bridge such divides. By contrast, we would expect that subsidiaries in CMEs require less central coordination. They may experience central coordination as unnecessary or, worse, as interfering with the existing more cohesive collectivities of practice. Based on these notions, we wish to explore how differences in organizational coordination or structure and institutional conditions interact to create different participation patterns and learning outcomes. We expect that differences in how situated learning plays out in subsidiaries depend on the extent of fit between the institutional context and the multinational's form of coordination. While we expect a good fit for subsidiaries that are embedded in a CME 
context and that are coordinated through decentralized authority (as with MNEs with a multidomestic structure; Bartlett and Ghoshal, 1989), we expect a poor fit if they are governed by high degrees of centralized authority (as for instance with MNEs with an international structure; Bartlett and Ghoshal, 1989). By contrast, we expect a good fit for subsidiaries that are embedded in an LME context that are coordinated through centralized authority, and a poor fit if they are governed by high degrees of decentralized authority. Table 1 depicts these relations.

Table 1 about here

\section{METHODS}

To explore our framework we conducted comparative case studies of the integration of new practices at four subsidiaries in two contrasting institutional settings of two rival MNEs, one Dutch and one British, in the European chemical industry. We selected these MNEs because they were similar in several respects, such as their industry and production techniques, but differed considerably in terms of their authority structure. Whereas the Dutch MNE operated a decentralized, multi-domestic structure (Bartlett and Ghoshal, 1989), the British MNE operated a more centralized, international authority structure. The difference in formal structure was expressed, among others, in differences in the allocation of responsibilities. For instance, at the British MNE, subsidiaries depended on headquarters for new product ideas (General Manager, R\&D Europe, British MNE). Instead, the Dutch MNE delegated considerable decision making to local subsidiaries, such as responsibilities for marketing and product development (Supply Chain Europe Director, Dutch MNE).

Instead, the subsidiaries were selected on the basis of their institutional host contexts. Specifically, we focused on two subsidiaries in the UK, an LME, and two subsidiaries in Germany, a CME (Hall and Soskice, 2001). All subsidiaries involved were engaged in the production of decorative paints, and asked by their respective headquarters to adopt new 
continuous improvement practices as part of their portfolio of practices. Thus, the research setup allowed us to control for several factors, while maintaining variation in the structure of the MNEs and the institutional contexts of their subsidiaries. This provided a fitting setting in which to explore whether and how the interplay between organizational and institutional structures affects participation patterns and learning outcomes (Table 2).

Table 2 about here

\section{Research sites}

The Dutch MNE is a Fortune Global 500 company operating in more than 80 countries. The division on which this study is based produces decorative paints. Although the division started standardizing and centralizing since 2000 to reduce costs, much decision-making still took place locally, such as marketing and production decisions. In response to increased industry pressure for cost reductions, in 2003 Dutch MNE introduced an improvement programme at various sites in Europe called 'Star Trek'. This involved the transfer of new continuous improvement practices such as Kaizen, Lean manufacturing, 5S and Six Sigma. Although each site was required to achieve results in various areas, such as the service level to customers, quality, cost per litre and stock levels, sites were given considerable flexibility to decide on how to achieve them.

The British MNE is a major chemical company in the UK whose activities extend to 50 countries. Similar to the Dutch MNE, this study is based on the strategically important paints division of the company. In the late 1990s, British MNE came under great pressure to achieve the maximum leverage out of a single project, hence it adopted an international structure to operating overseas. With the closures of local laboratories, subsidiaries grew dependent on the UK headquarters for new product ideas (General Manager, R\&D Europe). Consistent with this change was the introduction of a continuous improvement programme at the operational level called 'Paint Plant of the Future' across all sites in 2002 (Senior VP of Operations, British MNE). The required operational improvements included efficiency, cost, cycle times, and the amount of waste generated. British MNE’s approach to implementing changes was much more prescriptive and 
centralized than that of the Dutch MNE. In contrast to Dutch MNE, British MNE's subsidiaries had less autonomy, yet more central guidance to implement the continuous improvement practices. For example, various sites, including the UK and the German operations on which this study focuses, were audited against different matrices, given a score and provided detailed guidelines on how to reach higher score rating and improve key operational metrics (Senior VP of Operations, British MNE).

\section{Data collection and analysis}

Capturing learning from a situated learning perspective is a daunting exercise because all interactions or practices are potentially relevant and part of permanent learning (Handley et al., 2007). Handley et al. (2007: 181), therefore, suggest to "direct attention to likely points of transition and transformation”, as this makes different participation and practice patterns more observable. Hence, we focused on the integration of the new continuous improvement practices in the portfolio of practice of local workforces, as reflected in the change in their portfolio of practices. We also focused on the participation of different communities of practice in the transformation and accommodation of these practices.

For the purpose of this project, learning was categorized as high when the subsidiary workforce accommodated and sustained the new practices in their portfolio of practices. Conversely, learning was labelled as low when the subsidiary workforce did not include the new practices from headquarters in their portfolio, or when the adoption of new practices was not sustained. Learning was categorized as medium when the local workforce partially engaged in and sustained some of the practices they received from headquarters.

The studies were carried out between 2002 and 2003 (at the British MNE), and between 2006 and 2007 (at the Dutch MNE). The three-year gap in data collection between the two MNEs is due to the variation in the commencement and duration of the continuous improvement programmes. The Paint Plant of the Future programme of the British MNE started in 2002 and was completed in 2004. The Dutch MNE’s Star Trek programme was launched in 2003 and was completed in 2007. We tried to minimise the risk of generating rationalised interpretations by actors by accessing the two projects during their development rather than upon their completion. 
We collected our data through a combination of observational methods and semistructured interviews. We conducted 22 semi-structured formal interviews (13 at the Dutch MNE and nine at the British MNE), with interviewees ranging from the senior vice-president of operations down to site managers. The project coordinator and a second member of the research team conducted interviews at the UK site of the Dutch MNE, while the project coordinator and a third member of the research team conducted interviews at the German site of the Dutch MNE. The project coordinator also conducted the interviews at the two sites of the British MNE. The interviews lasted approximately one hour and were semi-structured. This format allowed us to have a set of fixed questions for comparison, but also provided flexibility to probe into actors' practices where needed. The interview protocol included questions on the MNEs' authority structures, the strategic objectives of the improvement programmes, the practice transfer and implementation processes, participation patterns, and the realized learning outcomes, among others. We recorded interviews to enhance the reliability of our findings, and collected participants' feedback on transcripts. The interviews were followed by a weeklong participant observation at each site, for which we obtained the permission of the sites' respective headquarters. Among others, these stays allowed us to conduct numerous informal talks with operators, team leaders and shift managers, and to collect company documents such as operation manuals and regulations.

At each site, a member of the research team acted as participant observer. The project coordinator was responsible for participant observation at the two sites of the British MNE, while the second and third member of the research team were responsible for participant observation at respectively, the UK site and German site of the Dutch MNE. Typically, we would first receive a tour of the factory. We would then receive proper work clothes, such as a work shirt and safety boots. We were also alerted to important health and safety measures, such as to wear protective earplugs in 'mixing', where the paint pigments are mixed with the solvent. Subsequently, we introduced ourselves and our project to the work force. At the sites there was ample opportunity for informal conversations on the shop floor with operators and team leaders. This was partially because of the frequent production halts that were necessary to 'clean the mixes down' between production runs of different shades of paint colours. During such breaks we would ask individual 
operators about improvements and changes in the way they ran the production line, often over ' $\mathrm{a}$ brew' (a cup of coffee or tea), and to demonstrate them on their machines. We also discussed their involvement in the implementation of the new practices at the site. We carefully made field notes of our observations on the shop floor, and also asked workers for permission to take notes during conversations. These notes were written in full at the end of each workday. Among others, this procedure helped highlight claims and apparent inconsistencies that could be verified or explored further the next day.

To enhance the validity of the data, we performed several types of data quality checks. For instance, claims from middle management about the performance of a particular work shift where checked against actual production figures that were posted on notice boards. Similarly, subsidiary and headquarter members' accounts were cross-checked. For example, claims by management about the implementation of new work practices were compared with observations on the shop floor; such as claims about health and safety measures, and the extent to which newly introduced standard operating procedures (SOPs) were followed. These observations revealed deviations, some minor (such as the limited use of mandatory earplugs), some major (such as checklists at quality control that were not followed), which were then examined further.

These methods worked relatively well for the purpose of our study. For instance, by first conducting interviews at headquarters, we gained insight into the type of practices that the subsidiaries were required to adopt. This made it easier in the participant observation-phase to detect variation in how these practices were incorporated into the portfolio of practices of the sites. Although we gained a good understanding of whether and how work practices had changed, the relatively brief periods spent at each site also meant that we did not achieve the same depth of understanding of the individual practices as could be achieved through other methods (see e.g. Nicolini, 2009a; 2010; 2011; cf. 'zooming in', or the detailed study of both the material and discursive accomplishments of practice, Nicolini, 2009b). Instead, our focus was on the connectedness of practice, and how variation in practice accommodation across sites was linked to contextual influences, such as the authority structure and the institutional contexts of the subsidiaries (cf. 'zooming out' on the ways in which practices are interconnected; Nicolini, 2009b). 
We subsequently analyzed our data through within-case analyses followed by cross-case analysis. The within-case analysis involved, first, the writing up of detailed case studies. This was done immediately after the field studies, which helped to overcome the lag in time between the studies during data analysis. In line with Strauss and Corbin (1998), field notes, transcribed interviews, and documents were manually coded using open and axial coding procedures. To verify the explanatory power of the codes, axial coding was carried out to relate sub-categories to the learning outcome (see the appendix for an illustrative list). The coding of the data was followed by cross-case analysis (Ragin, 1994) to identify similarities and differences across cases (George and Bennett, 2005). Following the 'pattern matching logic' (Pauwels and Matthyssens, 2004), we explored whether differences in participation patterns and subsidiary learning could be attributed to the extent of fit between MNE structure and host institutional environment.

\section{FINDINGS}

The case studies showed that the efforts to introduce continuous improvement practices produced considerable differences in learning across the subsidiaries. In spite of the similarity in acquired practices as well as the cost pressure felt by all subsidiaries, the German site of Dutch MNE and the local operation of British MNE displayed higher levels of learning than the British site of Dutch MNE and the German site of British MNE.

\section{Site 1: High learning at Dutch MNE's German site}

The German site was seen as one of the better operations of Dutch MNE, and demonstrated high learning in integrating the continuous improvement practices received from headquarters. Many of the new practices were accommodated in day-to-day operations, resulting in a considerable change in the site's portfolio of practices. These changes included, among others, the successful integration of the $5 \mathrm{~S}$ principles of work organization, changed filling processes for acticides, new eye shower installations, as well as a new system to track the service level of the site. In addition, the improvement system itself changed from a highly bureaucratic and cumbersome suggestion system to a system where suggestions for improvements produced 'simple orders for the 
workshop' (group advisor) which could be implemented on short notice (factory manager). Perhaps most importantly, management and operators jointly developed a set of behavioral standards to facilitate continuous improvement in daily operations. The resulting 'Production Role Model', with 'looking beyond one's own plate’ as one of its mottos, called for employee openness for change, and emphasized their responsibility to contribute to improvements. These new behavioral standards produced a plant-wide shift in attitude, which helped sustain the integration of the continuous improvement practices. In the words of the factory manager: 'The 'guidelines' are something you can fall back on. This is something the subordinate and the superior can refer to in any kind of discussion.’

One example is a learning incident in the filling section. Accidents with acticides, which are conservation agents that fight bacteria in paint filling stations, were frequent, because the filling station, which was run manually, had large open cans that had to be carried between the filling station and the mixer. This encouraged the group advisor to mobilize the search for ways to reduce injuries and man-hour loss caused by spills. This led to the discovery of a powder that could be used in place of acticides. However, it soon became clear that the powder itself, when mixed with sweat or water, led to injuries. Further search for a solution led to the introduction of mobile tanks that could be rolled to the mixers. In the end, the whole process of filling acticides became a closed system, which lowered the risk of accidents and injuries with the chemical substantially.

Participation patterns. The integration of the new continuous improvement practices at the German site involved a range of different communities of practice, such as plant management, group advisors, and skilled operators. While management was involved in formulating a vision and behavioural standards, it was the operators who were asked to transform these standards into routines that could be applied to their work area, such as mixing, filling or packaging. The participation of different communities of practice not only helped integrate the new practices in extant work practice, but also instilled a sense of mutual responsibility, which helped sustain continuous improvement. Or, in the words of a production group advisor: 'What has made its way to everyone are the guidelines. Workers were involved in their formulation. They find themselves and their ideas in them.' 
Extent of fit between organizational structure and institutional context. What facilitated the meaningful engagement of different communities of practice was that the decentralized structure of Dutch MNE proved supportive of the close relations between the different communities of practice at the site. For example, the decentralized structure supported the low professional distance between middle management, supervisors, and operators on the shop floor, owing to their shared technical or vocational training and professional careers. The workforce respected management as most managers had a history of apprenticeship or trade training with the company. For instance, the plant's production advisor had worked himself up from the shop floor and was a 'Meister', or master craftsman. He regularly interacted with the group advisors of different departments. Similarly, the site manager was promoted from the unskilled worker level to the top managerial position. This provided him with not only intimate know-how of the production processes, but also sheer respect for production workers. The decentralized structure and close relations between different communities encouraged, among others, the allocation of considerable responsibility to the work force to contribute to production improvements. As indicated by the factory manager of the wall paint plant:

'You have to accept that they know a hell of a lot. They know three times more than the stupid manager knows. He may know more about planning issues, but machine knowledge and understanding the problems, there the man in the line knows best. And one has to appreciate that. If this is not the case, we, I have a problem.'

Similarly, the decentralized structure helped accommodate institutional requirements for codetermination. The works council, which has a strong role in the collaborative institutional system of Germany, maintained favourable relations with management (factory manager). It participated constructively in the integration of the new practices (production advisor), and was instrumental in the implementation of a new incentive system.

\section{Site 2: Low learning at Dutch MNE's UK site}

By contrast, the UK site of Dutch MNE faced considerable challenges in integrating the continuous improvement practices into the subsidiary's portfolio of practices, and demonstrated low learning. Several initiatives were employed to integrate the continuous improvement practices 
at the site. A consultancy firm set ambitious new production targets, and standard operating procedures (SOPs) were rewritten. Operators received external training in health and safety standards, and a number of modules on 5S and Kaizen were offered which were partially funded with subsidies provided by the UK government to minimize the loss of manufacturing jobs (site manager).

Yet there was little indication that these external efforts translated into sustained changes in the portfolio of practices at the UK site. For instance, the new SOPs were not communicated to new employees, and operators claimed to do very little differently, and that 'the actual way you do your job doesn’t change' (operator). As one operator summed up '[New SOPs] are brought in, people hear about it, but people tend to do it their own way.' Operators also expressed that they could not produce at the new required filling speeds owing to paint spillage. However, this did not encourage management to change targets, with the result that production figures had been reported on a machine that had not even operated (team leader). Finally, the low learning was also exemplified by the 'fizzling away over the last one and a half to two years' of the 5S housekeeping initiative (operator). This sentiment was reflected by management. As the operations director summed up: 'So we have made a few demonstrations, improvement projects here and there. But it has not become a way of life.'

Participation patterns. In sharp contrast to Dutch MNE’s German site, where employees from across the hierarchical range were involved in the integration of new practices, at the UK site the scope of meaningful participation was confined to management and external consultants. Although operators participated in external training programmes, they were not involved in generating solutions to how the continuous improvement practices could be integrated in daily work practice. Rather, the solutions from management and external consultancy firms were imposed upon them. Operators felt the new practices were presented as a case of 'implement and carry on', and many considered Star Trek to be 'a management thing' (operator). The limited participation of operators and team leaders in the integration of the practices mirrored the strongly felt divide between management and the shop floor. An operator explained that management 'either does not listen to suggestions, or operatives are not asked about issues.' In contrast to the German site, management was perceived to have relatively limited understanding of plant 
operations, and preferred to distance itself from shop floor activity.

Extent of fit between organizational structure and institutional context. Thus, whereas the decentralized structure worked well in Germany’s collaborative institutional context, where it allowed Dutch MNE’s German site to accommodate pressures for codetermination and supported cooperative relations between different occupational groups, at the British subsidiary the lack of clear guidance from headquarters was a source of frustration. It hampered the bridging of the strongly felt divides between different occupational groups. While improvements were mainly expected to come from the shop floor, there was only limited respect for and understanding of local capability. 'Management should take much more control over the plant, be part of the team, and have a clear idea of what people are actually doing' (operator with six years of experience on the blue shift that runs from 14:00 to 22:00). In the words of the site manager:

'There is a lot from headquarters that is relevant but we are asked further questions like "Where do you see yourself in the future? What is your local vision?” We do not know how these translate to the operational level'.

The result was that solutions to how new practices were to be integrated were superficial, and that there was little actual change in the portfolio of practices-in-use at the site. In the words of the business unit's improvement manager: 'If I had [to rate the extent to which the principles had been taken on board on] a scale from 1 to 10 , then I would say we are on 1 out of $10^{\prime}$.

\section{Site 3: Medium learning at British MNEs German site}

Although the German site of the British MNE faced difficulties, it achieved partial integration of the continuous improvement practices by emphasizing the behavioural aspects of the 'Paint Plant of the Future' programme. It set itself the goal of demonstrating the best in class performance for quality, cost and customer service in Europe through passionate, capable and motivated people (Continuous Improvement document Germany). The site was initially scanned for improvements by a consultancy firm which developed 11 different projects from quality acceleration to the organization of manpower. Yet these only served to guide management in creating a work environment that encouraged employee involvement in continuous improvement. The most important initiative involved eliminating a managerial level—-that of operations management and 
quality assurance — and enhancing jobs of operators: 'We are encouraged to take decisions and be accountable for results' (operator). In addition, a competency-based selection process, which was unique for Germany, was introduced:

'People had to apply for their jobs. Those who passed became maintainers. The selection criteria were set up by an external company. It was sort of training on-the-job and a series of seminars were provided off-the-job. It meant empowerment to operators' (managing director).

The new behavioural guidelines were manifested in new improvement practices. For example, the cycle time was reduced from 20 hours to 10 hours by shortening the distances that raw materials travelled in the manufacturing process. Similarly, test cycle times were reduced from six hours to four hours with some of the operators testing the product themselves rather than forwarding it to the quality control department to pass or fail. Yet practices were not fully sustained as there was resistance from some of the operators. Although key metrics required discipline in handling waste and material loss on the shop floor, a number of operators neither displayed discipline nor felt urgency, and a number of operators preferred to work the 'old way': 'We were told to do it and we did it' (operator).

Participation patterns. The partial integration of practices at the German site was realized via the participation of various CoPs including plant management, first-line supervisors and operators. Plant management promoted a culture of open communication, early warning of problems and a 'can-do approach' in order to enable and sustain change (shift manager): 'We set up a culture for people to ask for help. We were used to saying, 'we will fix it for you'. With the changes, people are encouraged to fix their own problems. If they make a wrong decision, they are not penalized (managing director). A number of operators participated in the integration of practices through focused improvement teams in both mixing and filling lines. They received onthe-job training and series of off-the-job seminars to improve performance measurements and control. First-line supervisors also ensured that behavioural guidelines and day-to-day improvements were followed on principles of openness and transparency. They aimed to garner the support of operators by communicating strategic goals in a language to which the operators could relate: 
'If they understand that that is money, cash going through the drains, then they will probably respond better. Or as my Austrian colleague here sometimes says 'if we save from $\mathrm{X}$ to $\mathrm{Y}$, that is so many VW Golfs'. Just express that in cars. If we throw 57 cars in the bin in a year that is probably a lot of money. So, try and bring that nearer to the people so that they know what they are fighting for.' (managing director)

Extent of fit between organizational structure and institutional context. The engagement of various CoPs in the integration of practices was hindered by British MNE's international MNE structure. The centralized authority associated with this structure was not highly appreciated by the German subsidiary. What the structure offered in terms of control of operational procedures and standards conflicted with the German institutional demand for collaborative means of setting standards. For example, team leaders found it challenging to own quality control problems owing to the involvement of the parent company: 'All of a sudden, there comes a parent company, puts a foot on us and says "we will guide you through some of our standards. We have got company standards that you have to follow". People see that sometimes as pain' (team leader). The divergence of some of the operators' interests from the HQ mandate led to defiance: "The operators check that the products have the right label, that the right ingredients go into it. If you ask me if people are checking against the standards, then I would say there is more windowdressing” (shift manager at the German site).

The centralized authority of the HQ was partially offset by efforts of local management to encourage the participation of various communities in the integration of new practices. For example, similar to the German site of the Dutch MNE, some of the management team members had risen from the ranks of apprenticeship. They were familiar with and could relate to problems arising from the shop floor. Although the managing director was recruited externally, his experience at the company and his respect for local capability also earned him the respect of the workforce. In addition, the institutional requirement for codetermination was accommodated by management, who welcomed works council involvement in the integration of the new practices. For instance, the proposal by management to introduce a skill enhancement model initially led to scepticism in the works council: 'There were harsh discussions at the beginning. They [the works 
council] said "you are taking advantage of people. You are creating different work classes”.' (manager of the German site). Ultimately, the works council members were invited to attend skill enhancement workshops and to review selection processes. Their engagement in this change process enabled them to see the benefit to the workers and to support management.

\section{Site 4: High learning at British MNE's UK site}

The UK site of British MNE was more successful than the German site in integrating continuous improvement practices, and demonstrated high learning. In its aim to be the first choice manufacturer for the European supply chain, the site worked to improve its operational efficiency, cycle time, 'right-the-first-time' and yield loss. Similar to that at the German site (site 3), the focus was on the behavioural aspects of continuous improvement to achieve key performance targets. This included replacing supervisors with team leaders, changing the work culture and introducing self-managed teams. For instance, with respect to self-management, or the absence of direct supervision of production, our observations and informal talks showed that the teams produced their own targets and reported their successes and failures, as well as the reasons underlying failures, to the management team on a daily basis. They nominated their leader on a rotating basis. An old key with a tag would be worn by the leader of the team for the day who would have the final judgment on issues, chair the morning meetings and report performance scores to his members. The new behavioural standards were widely accepted and sustained as new practices in production. For example, operators developed the idea of fitting a filter in the form of a mesh disc that pushed rubbish down before the paint was fed to four transfer lines. This improved the quality of paint, reducing contaminants from 250 micron to 150 micron on a paint feeding point.

Participation patterns. The integration of continuous improvement practices at the UK site required the participation of different CoPs such as the plant management, team leaders and operators. Management engaged with team leaders and operators, believing that 'the management team are out there to serve the operators who actually do the job' (manager of the UK site). The most notable initiative - the self-managed teams—showed the dedication of highly committed operators, volunteering to serve as trainers, to improve processes. There were daily toolbox 
meetings at ten in the morning where 'guests', i.e. the site manager, the plant manager, the engineer and anyone else who could help the operators achieve their production rates, were invited to discuss the reasons for underperformance. One of the operators would chair the meeting and challenge the management team to put in place technicalities that would improve operations, and have them commit to a deadline. The emphasis on self-management was complemented by training to empower workers:

'One of the things we did is that we really spent long long time in training our operators, real basic understanding of our plant. We trained those guys on actually really working the plant, touching the pipe work, seeing where things go, where does that go, what does this do, when you push that, what happens. These guys almost memorized the number of every valve in that plant and what it did and where does it lead to and what would happen in an emergency situation.' (manager of the UK site)

Extent of fit between organizational structure and institutional context. The participation of various CoPs in the integration of practices was supported by an international MNE structure. There was no resistance to central guidance offered by HQ and the structure accommodated the institutional demand for unilateral control and strong management-worker separation. Tools and techniques were developed to 'help sites understand their current performance, identify where the greatest gains are to be had, and suggest practical means of achieving these gains' (internal report on yield study, p. 6). 'We receive instructions to determine the product stream model closest to that of the unit to be considered, take appropriate best practice percentage figures and convert them into volumes and costs, complete much of the current practice figures and calculate the financial gap' (manager of the UK site).

In line with the institutional feature of the UK, there were no collective arrangements to represent employees' interests in decision making. Rather, direct employee participation was encouraged to have operators take on board new practices.

When the watercolour [division] was sold off, we had to be self-sufficient up here, and change the culture. We are it, there is no one else. That is when we really got involved with our people. We engage them and try to make sure that- $[\mathrm{X}]$ is a small 
site now—flourishes and grows...We have been very keen—because I am from an operator background—on bringing our operators through. (manager of the UK site)

He and his team leaders saw value in the local capabilities of his workforce and perceived the role of the management team as simply assisting them. 'We had loads of secondments. Ben, the young graduate guy who has just come to join us from the university last year was the plant manager of [paint brand]. He went off to do some university work. His number two, his replacement, was an operator. The operator ran that plant and was the plant manager for two months. That is good stuff' (team leader).

\section{DISCUSSION}

The findings of our case studies are largely in line with the predictions of our framework. As expected, we observe high levels of learning where there is a good fit between the MNE structure and the institutional host context. Yet, we also find that the reverse-low learning under conditions of poor fit—does not necessarily hold. When the institutional environment and the MNE coordination structure are less aligned, actions such as participative leadership or the mobilization of employment involvement schemes may assume a significant role in promoting participation across CoPs, and hence affect learning outcomes (site 3). This suggests that while a fit between MNE structures and institutional contexts matters, it does not determine learning outcomes as actors can actively create solutions to their problems under conditions of a poor fit. Below, we discuss these findings in more detail (see Figure 1).

Figure 1 about here

Dutch MNE’s decentralized authority granted its British and German sites considerable operational flexibility, but also left them less supported. As suggested by our framework, the decentralized authority worked well at the German site of Dutch MNE (site 1). The structure of Dutch MNE allowed the German site to cater for the involvement of works council members, and 
support the collective participation and authority sharing among different CoPs resulting from the German apprenticeship system. This finding also reflects on work in comparative institutionalism that highlights how the vocational training system and organizational career paths in Germany impact, for instance, the cohesion and exchange of knowledge among functionally related professional groups (e.g., Ferner et al., 2001; Whitley, 2007). Thus, the authority delegated through a decentralized MNE structure was well-aligned with the relatively fluid epistemic boundaries between different CoPs in Germany, which facilitated collective participation in the integration of new practices.

By contrast, the integration of practice at the UK site of Dutch MNE (site 2) was unsuccessful. This appeared to stem from a misalignment between Dutch MNE's decentralization of decision-making responsibilities and the need for more directive action due to the lack of collective arrangements to ensure the interest and participation of professional groups outside of management. In liberal market economies, such as the UK, loose inter-firm networks and relatively detached ties with capital nurture extensive unilateral control by management and strong management-worker separation (Hall and Soskice, 2001). In addition, such settings offer fewer opportunities for continuous exposure to combined practical and academic training in the higher education system (Lane, 1996). As illustrated by Dutch MNE’s UK site, managers therefore tend to be "generalists and their approach to management is more likely to be generally administrative and financial than technical” (Sorge, 1995: 251). This suggests that a more direct involvement of employees is required to ensure collective participation across CoPs (see also Tüselmann et al., 2006), and to ensure meaningful participation in the integration of new work practices. As our framework suggests, the Dutch MNE's decentralized organizational structure did not meet this requirement for more direct action from the centre to bridge the epistemic barriers.

Instead, British MNE's organizational structure appeared to be more effective in providing the centralized authority required to bridge internal epistemic barriers. Unlike the UK site of the Dutch MNE (site 2), the UK site of British MNE (site 4) received clear guidance in terms of operational goals and means of reaching these through explicit standard operating procedures. In the absence of collective arrangements, as for instance in Germany, the centralized structure of the British MNE promoted direct employee participation in the integration of new 
work methods in the unit's portfolio of practices. Thus, the MNE structure of the British MNE appeared better aligned with the host country institutional demands for central directives. Not only is this finding in line with our framework, in conjunction with Dutch MNE’s German site, it also illustrates that high learning across CoPs can be achieved in contrasting national institutional contexts (cf. Roberts 2006), albeit under different organizational structural conditions.

While our case findings highlight that the interaction between formal structures at different levels matters, they also indicate that structural conditions do not necessarily determine learning outcomes, as is illustrated by the German site of the British MNE (site 3). In line with our framework, the British MNE's international structure appeared less supportive of learning efforts at the German site than at the UK site. Its more directive structure tended to give less importance to harnessing the constructive or partnering role of collective arrangements in Germany's more coordinated institutional environment, and hindered the engagement of different CoPs in transforming new practices to the local context. As a result, British MNE's German site experienced slow change and reduced initiative. Yet while we would expect to observe low learning at the site given the poor fit between British MNE's organizational structure and the German institutions, the site displayed medium learning. Despite the central coordination of the parent company, the German site (site 3) was able to encourage meaningful engagement and participation of various CoPs through participatory leadership and the activation of employee involvement systems. Thus, the British MNE’s German site illustrates that the ambiguity resulting from structural misfit can also create room for agency that can partially offset the effects of institutional and organizational structures.

\section{CONCLUSIONS}

Practice-based studies are paying increased attention to how institutional factors impact the emergence, change and stabilization of organizational practice (e.g. Gherardi and Perrotta, 2011; Lounsbury and Crumley, 2007). In this study, we have sought to add to this emergent line of research by highlighting a second set of influences through which institutions affect situated learning, namely through the interplay between the institutional and organizational structures in 
which organizational 'sites of knowing' (Nicolini, 2011) are embedded. To this end, we studied the introduction of new practices at four subsidiaries of two MNEs and explored how differences in organizational coordination and institutional conditions interacted to create differences in situated learning processes across the four sites.

The outcomes of our study make several contributions to practice-based studies. First, in line with our framework, our case findings suggest that inclusive participation patterns and high learning outcomes are associated with a good fit between organizational and institutional structure. This finding rests on the insight that institutional structures give rise to variations in the epistemic boundaries and bridges, or epistemic topography, in organizations. A learning related feature of this epistemic topography is the question of how cohesive and compartmentalized an organization's communities of practice are, as this has a direct bearing on participation patterns. Given that the cohesiveness and compartmentalization of communities of practice can vary, different kinds of organizational structures play either a more enabling or constraining role for learning, depending on the extent to which they bridge a given compartmentalization or interfere with a given cohesiveness. Hence, we extend contributions emphasising the crucial role of organizational coordination for learning across epistemic divides (Brown and Duguid, 2001; Macpherson and Clark, 2009) by specifying this relationship as one of alignment between institutionally structured epistemic topographies and organizational structures.

Second, our findings also illustrate the potential value of insights from comparative institutionalism for practice-based studies. Thus far, most practice-based studies that focus on institutions have drawn on insights from organizational institutionalism. Applied to practice-based studies, organizational institutionalism helps us understand how institutionalized rules, norms and beliefs and their dynamics may affect organizational practice within an organizational field (e.g. Gherardi and Perrotta, 2011; Lounsbury, 2008; Lounsbury and Crumley, 2007). However, this stream of research does not capture that the organization of practice itself is subject to higherorder, societal institutions and therefore differs between countries. Given that societal institutions specify a higher level of constraint and opportunity for organizational action (Thornton and Ocasio, 1999), it is useful to examine their effects on practice separately from institutional influences at the level of the organizational field. We, therefore, draw on comparative 
institutionalism that highlights how societal institutions such as the education system and industrial relations system shape socio-professional identities and divisions within organizations (e.g. Hall and Soskice, 2001; Whitley, 1999; 2007). These, in turn, shape epistemic communities that are rooted, often, in national communities (Djelic and Quack, 2010). Thus, comparative institutionalism is particularly suited to extending our understanding of how the boundaries between different communities of practice, and the relations between them, may vary across national institutional contexts.

Finally, while our aim was to highlight how institutional and organizational structures jointly affect situated learning, a focus on institutions does not necessarily imply the absence of actors or agency (Lounsbury, 2008). As our findings at the German site of British MNE highlight, institutional and structural contradictions may also create space for agency or innovative organizational responses to problems. This resonates with recent contributions in both neoinstitutional and comparative institutional literatures (e.g. Battilana and Dorado 2010; Crouch, 2005) and with works that link institutional theory to practice based studies (e.g. Kakavelakis and Edwards, forthcoming; Lounsbury, 2008). We align ourselves with the view that actors can respond actively and reflexively to misalignments between institutionalized rules and situational demands by mobilizing resources (e.g. Greenwood et al., 2011). Institutional rules can, therefore, be used creatively (Hall and Thelen, 2009; Herrigel, 2008) to cope with conflicting requirements stemming from different formal structures. For example, the German system of codetermination proved to be an institutional resource that actors at site 3 could mobilize against the constraining structure of the British parent.

There is room for further development in this area, in particular along three approachesdiscourse analysis, actor-network theory and semiotics—-that represent important potential sources of insight into the dynamics of institutional work. However, given that a significant theoretical and empirical tradition is associated with each of these three domains, it is beyond the scope of our paper to address this here. Nonetheless, we would like to underscore the potential that practice studies have in advancing our understanding of institutional work. Our study also suffers from the limitations associated with comparative case study design. The method adopted offers control in case comparison and enables a holistic case-oriented approach to data analysis for more 
comprehensive explanations. Its aim is not to describe rich data but to seek control for comparability and analytical generalizability (see George and Bennett, 2005 for an elaboration). Consequently, our brief stays at the respective sites could not provide the depth of information necessary to trace the processes leading up to certain outcomes as would be revealed by interpretivist methods (see e.g. Nicolini, 2009b).

In spite of these limitations, the findings offer at least two potentially rewarding avenues for future research. First, our findings suggest the need for a more systematic examination of how structural contradictions provide actors with varying opportunities and constraints to mobilize resources, including political, for agency. This would progress the emergent works on politics, conflict and negotiations in practice based studies (e.g. Contu and Willmott, 2003; Fox, 2000; Heizmann, 2011; Kakavelakis and Edwards, forthcoming; Mørk et al., 2010; Ormrod et al., 2007; Roberts, 2006). We also believe that further comparative work is called for that pays close attention to how institutional patterns structure organizational career paths (Whitley, 2007). Examining these paths and their mobility implications for members of communities of practice within and across organizations is important to better understand the changing nature of epistemic topographies and participation patterns, and to refine our understanding of how practice-based work and situated learning differs across contexts.

\section{REFERENCES}

Amin and Roberts (2008). 'Knowing in action: Beyond communities of practice', Research Policy, 37: 353-369.

Bartlett, C., and Ghoshal, S. (1989). Managing Across Borders: The Transnational Solution. Boston: Harvard Business School Press.

Battilana, J. and Dorado, S. (2010). 'Building sustainable hybrid organizations: The case of commercial microfinance organizations', Academy of Management Journal, 53: 1419-1440.

Brown, J. S. and Duguid, P. (1991). 'Organizational learning and Communities-of-practice: Toward a unified view of working, learning, and innovation’, Organization Science, 2: 40-57.

Brown, J. S. and Duguid P. (2001). 'Knowledge and organization: a social-practice perspective', Organization Science, 12: 198-213. 
Cook, S. D. N. and Yanow, D. (1993). 'Culture and organizational learning', Journal of Management Inquiry, 2, 373-390.

Corradi, G., Gherardi, S., and Verzelloni, L. (2010) 'Through the practice lens: Where is the bandwagon of practice-based studies heading?’, Management Learning, 41: 265-283.

Contu, A. and Willmott, H. (2003). 'Re-embedding situatedness: The importance of power relations in learning theory’, Organization Science, 14: 283-296.

Crouch, C. (2005). Capitalist Diversity and Change. Recombinant Governance and Institutional Entrepreneurs. Oxford: Oxford University Press.

Delmestri, D. and Walgenbach, P. (2005). 'Mastering techniques or brokering knowledge? Middle managers in Germany, Great Britain and Italy’, Organization Studies, 26: 197-220.

Djelic, M.-L. and Quack, S. (2010). Transnational Communities: Shaping Global Economic Governance. Cambridge: Cambridge University Press.

Dunning, J. H. (1998). 'The changing geography of foreign direct investment' in N. Kumar, (ed.), Internationalization, Foreign Direct Investment and Technology Transfer: Impact and Prospects for Developing Countries. London: Routledge.

Elkjaer, B. (2003). 'Social learning theory: Learning as participation in social processes' in Easterby-Smith, M. and Lyles, M.A. (eds), The Blackwell Handbook of Organizational Learning and Knowledge Management, pp. 38-53. Malden: Blackwell Publishing.

Ferner, A., Quintanilla, J. and Varul, M. Z. (2001). 'Country-of-origin effects, host-country effects, and the management of human resources in multinationals: German companies in Britain and Spain', Journal of World Business, 36: 107-127.

Fox, S. (2002) 'Communities of practice, Foucault and actor-network theory', Journal of Management Studies, 37: 853-868.

Geiger, (2009). 'Revisiting the concept of practice: Toward an argumentative understanding of practicing’, Management Learning, 40: 129-144.

George, A. L. and Bennett, A. (2005). Case Studies and Theory Development in the Social Science. Cambridge, Mass.: MIT Press.

Gherardi, S. (2000). 'Practice-based theorizing on learning and knowing in organizations: Introduction to the special issue on knowing in practice’, Organization, 7: 211-223.

Gherardi, S. (2006). 'Practice? It’s a matter of taste!', Management Learning, 40: 535-550.

Gherardi, S. and Nicolini, D. (2002) 'Learning in a constellation of interconnected practices: Canon or dissonance', Journal of Management Studies, 39(4): 419-436.

Gherardi, S. and Perrotta, M. (2011) 'Egg dates sperm: A tale of practice change and its stabilization’, Organization, 18(5): 595-614.

Ghoshal S, and Nohria N. (1993). 'Horses for courses: organizational forms for multinational corporations', Sloan Management Review, Winter: 23-35.

Giardini, A., Rüdiger, K., and Müller-Camen, M. (2005). 'HRM in the German business system: A review', Management Revue, 16: 63-80.

Greenwood, R., Raynard, M., Kodeih, F., Micelotta, E. R. and Lounsbury, M. (2011). ‘Institutional 
complexity and organizational responses’, Academy of Management Annals, 5: 317-371.

Hall, P. A., and Gingerich, D. W. (2009). 'Varieties of capitalism and institutional complementarities in the political economy', British Journal of Political Science, 39: 449-482.

Hall, P. A. and Soskice, D. (2001). Varieties of Capitalism: The Institutional Foundations of Comparative Advantage. Oxford: Oxford University Press.

Handley, K., Sturdy, A., Fincham, R. and Clark, T. (2006). 'Within and beyond communities of practice: Making sense of learning through participation, identity and practice', Journal of Management Studies, 43: 641-653.

Harvey, C. and Maclean, M. (2010). 'Transnational boards and governance regimes: A FrancoBritish comparison’, in M.-L. Djelic and S. Quack (eds), Transnational Communities: Shaping Global Economic Governance, pp. 107-129. Cambridge: Cambridge University Press.

Heizmann, H. (2011). 'Knowledge sharing in a dispersed network of HR practice: Zooming in on power/knowledge struggles’, Management Learning, 42: 379-393.

Hong, J. F. L., Easterby-Smith, M. and Snell, R. S. (2006). 'Transferring organizational learning systems to Japanese subsidiaries in China’, Journal of Management Studies, 43: 1027-1058.

Kakavelakis, K. and Edwards, T. (Forthcoming). 'Situated learning theory and agentic orientation: A relational sociology approach’, Management Learning, doi:10.1177/1350507611427233.

Kogut, B., and Zander, U. (1993). 'Knowledge of the firm and the evolutionary theory of the multinational corporation’, Journal of International Business Studies, 24: 625-645.

Lane, C. (1996). 'The social constitution of supplier relations in Britain and Germany: An institutionalist analysis' in Whitley, R. and Kristensen, P. H. (eds), The Changing European Firm: Limits to Convergence, pp. 271-304. London: Routledge.

Lave, J. and Wenger, E. C. (1991). Situated Learning: Legitimate Peripheral Participation. Cambridge: Cambridge University Press.

Lindkvist, L. (2005). 'Knowledge communities and knowledge collectivities: A typology of knowledge work in groups', Journal of Management Studies, 42: 1189-1210.

Lounsbury, M. (2008) 'Institutional rationality and practice variation: New directions in the institutional analysis of practice', Accounting, Organizations and Society, 33(4-5): 349-361.

Lounsbury, M. and Crumley, E.T. (2007) 'New practice creation: An institutional perspective on innovation’, Organization Studies, 28(7): 993-1012.

Macpherson, and Clark (2009). 'Islands of practice: Conflict and a lack of "community" in situated learning’, Management Learning, 42: 551-568.

Mørk, B.E., Aanestad, M., Hanseth, O. and Grisot, M. (2008) 'Conflicting epistemic cultures and obstacles for learning across communities of practice’, Knowledge and Process Management, 15(1): 12-23.

Mørk, B.E., Hoholm, T., Ellingsen, G., Edwin, B. and Aanestad, M. (2010) 'Challenging expertise: On power relations within and across communities of practice in medical innovation', Management Learning, 41(5): 575-592.

Newell, S., Robertson, M., Scarbrough, H, and Swan, J. (2009). Managing Knowledge Work and Innovation, $2^{\text {nd }}$ edition. Hampshire: Palgrave Macmillan. 
Nicolini, D. (2009a) 'Articulating practice through the interview to the double', Management Learning, 40(2): 195-212.

Nicolini, D. (2009b) 'Zooming in and out: Studying practices by switching theoretical lenses and trailing connections’, Organization Studies, 30(12): 1391-1418.

Nicolini, D. (2011) 'Practice as the site of knowing: Insights from the field of telemedicine', Organization Science, 22(3): 602-620.

Nicolini, D., Gherardi, S. and Yanow, D. (2003) Knowing in Organizations: A Practice-Based Approach. Armonk, NY: ME Sharpe.

Nicolini, D., Mengis, J. and Swan, J. (forthcoming) 'Understanding the role of boundary objects in cross-disciplinary collaboration’, Organization Science. doi 10.1287/orsc.1110.0664.

Orlikowski, W.J. (2002) 'Knowing in practice: Enacting a collective capability in distributed organizations’, Organization Science, 13: 249-273.

Ormrod, S., Ferie, E., Warren, F. and Norton, K. (2007). 'The appropriation of new organizational forms within network of practice: Founder and founder-related ideological power', Human Relations, 60: 745-767.

Pauwels, P. F. J. and Matthyssens P. (2004). 'The architecture of multiple case study research in international research', in R. Marschan-Piekkari and C. Welch (eds.), Handbook of Qualitative Research Methods for International Business, pp. 125-143. Cheltenham: Edward Elgar Publishing.

Raelin, J.A. (1997) ‘A model of work based learning’, Organization Science, 8: 563-578.

Roberts, J. (2006). 'Limits to communities of practice', Journal of Management Studies, 43: 623639.

Sorge, A. (1995). 'Labour relations, organization and qualifications'. In: A.W. Harzing, J. van Ruysseveldt, and J. van Hoof (Eds.) Comparative Industrial \& Employment Relations. London: Sage, pp. 243-66.

Swan, J. and Scarborough, H. (2005). 'The politics of networked innovation', Human Relations, 58: 913-943.

Swan, J., Scarbrough, H. and Robertson, M. (2002). 'The construction of "communities of practice” in the management of innovation', Management Learning, 33: 477-496.

Strauss, A. and Corbin, J. (1998). Basics of Qualitative Research: Techniques and Procedures for Developing Grounded Theory. Thousand Oaks, CA: Sage Publications.

Tagliaventi, M. R. and Matterelli, E. (2006). 'The role of networks of practice, value sharing and operational proximity in knowledge flows between professional groups', Human Relations, 59: 291-319.

Thompson, M. (2005). 'Structural and epistemic parameters in communities of practice', Organization Science, 16: 151-164.

Thornton, P.H. and Ocasio, W. ( 1999). 'Institutional logics and the historical contingency of power in organizations: Executive succession in the higher education publishing industry, 19581990’, American Journal of Sociology, 105: 801-843. 
Tönnies, F. (1912) Gemeinschaft und Gesellschaft: Grundbegriffe der reinen Soziologie (2 ${ }^{\text {nd }}$ ed.), Berlin: Karl Curtius.

Tüselmann, H.-J., McDonald, F., and Thorpe, R. (2006). 'The emerging approach to employee relations in German overseas affiliates: A role model for international operation?', Journal of World Business, 41: 66-80.

Wenger, E. C. and Snyder, W. M. (2000). 'Communities of practice: The organizational frontier', Harvard Business Review, 78: 139-145.

Wenger, E., McDermott, R. and Snyder, W. M. (2002). Cultivating Communities of Practice. Boston: Harvard Business School Press.

Wenger, E.C. (1998). Communities of Practice: Learning, Meaning and Identity. Cambridge: Cambridge University Press.

Whetten, D.A. (2009). 'An examination of the interface between context and theory applied to the study of Chinese organizations’, Management and Organization Review, 5: 29-55.

Whitley, R. (1999). Divergent Capitalisms: The Social Structuring and Change of Business Systems. Oxford: Oxford University Press.

Whitley, R. (2007). Business Systems and Organizational Capabilities: The Institutional Structuring of Competitive Competences. Oxford: Oxford University Press.

Yakhlef, A. (2010). 'The three facets of knowledge: A critique of the practice-based learning theory', Research Policy, 39: 39-46.

Yin, R. K. (2003). Case Study Research. Design and Methods. Thousand Oaks/London/New Delhi: Sage. 
Table 1. Extent of fit between organizational structure and institutional context

\begin{tabular}{lll}
\hline \multirow{2}{*}{ MNE structure } & \multicolumn{2}{c}{ Institutional context } \\
\cline { 2 - 3 } Decentralized & \multicolumn{1}{c}{ CME } & \multicolumn{1}{c}{ LME } \\
MNE structures & $\begin{array}{l}\text { Good fitDecentralized authority } \\
\text { does not interfere with } \\
\text { constellations of CoPs. }\end{array}$ & $\begin{array}{l}\text { Poor fit } \\
\text { Decentralized authority does not } \\
\text { integrate divides between } \\
\text { centralized MNE }\end{array}$ \\
& $\begin{array}{l}\text { Poor fit } \\
\text { structures }\end{array}$ & Centralized authority interferes \\
& with constellations of CoPs. & Contralized authority integrates \\
& & constellations of CoPs. \\
& & \\
\hline
\end{tabular}


Table 2. Structural Characteristics and Host Institutional Contexts of Research Sites

\begin{tabular}{lcc}
\hline \multicolumn{1}{c}{ MNE structure } & \multicolumn{2}{c}{ Institutional context } \\
\cline { 2 - 3 } Decentralized & German site of Dutch MNE & British site of Dutch MNE \\
MNE structure & (Site 1) & (Site 2) \\
Centralized & German site of British MNE & British site of British MNE \\
MNE structure & (Site 3) & (Site 4) \\
\end{tabular}


Figure 1. Subsidiary Learning Patterns by MNE Structure and Host Institutional Context

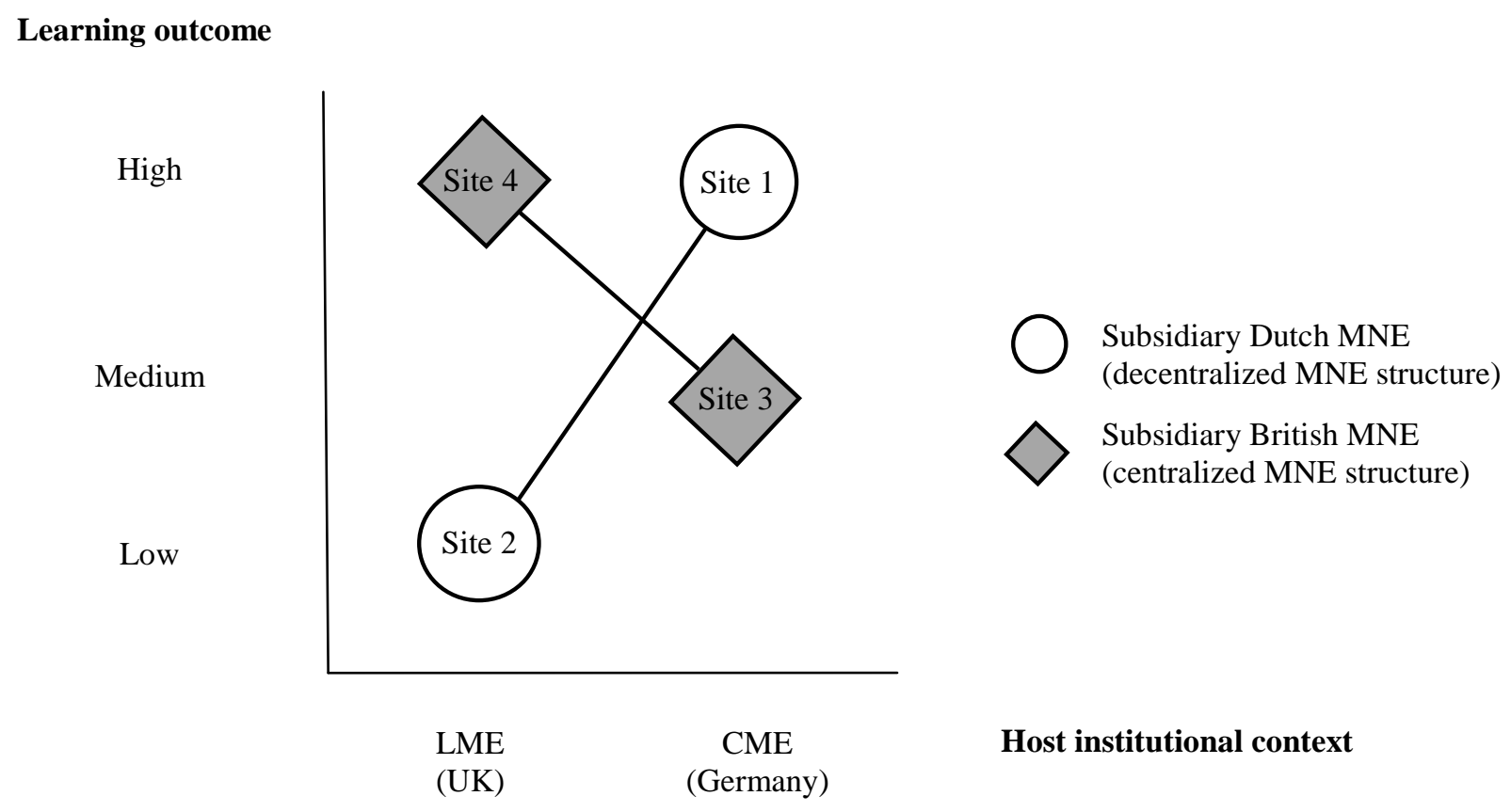




\begin{tabular}{|c|c|c|c|c|c|}
\hline $\begin{array}{l}\text { Categories related } \\
\text { to the learning } \\
\text { outcome }\end{array}$ & Sub-categories & Dutch Chem’s German site & Dutch Chem's UK site & British Chem’s German site & British Chem’s UK site \\
\hline $\begin{array}{l}\text { MNE structure } \\
\text { (i.e. the extent to } \\
\text { which } \\
\text { capabilities and } \\
\text { decision-making } \\
\text { are decentralized } \\
\text { and high } \\
\text { interdependency } \\
\text { of work between } \\
\text { subsidiaries and } \\
\text { HQ exists) }\end{array}$ & $\begin{array}{l}\text { International/M } \\
\text { ulti domestic } \\
\text { form of MNE } \\
\text { structure }\end{array}$ & $\begin{array}{l}\text { "We just buy brands and we keep } \\
\text { to a pre-existing brand". } \\
\text { "Still, there is a lot of local decisic } \\
\text { choose, assets they have... The [pa } \\
\text { business. Painters are not organize } \\
\text { regionally" } \\
\text { "There are so many different mod } \\
\text { some are very local, some are very } \\
\text { local”. }\end{array}$ & $\begin{array}{l}\text { ose brands. We build [our brand] next } \\
\text { 1-making about marketing, recipes they } \\
\text { nts] business is very much a local } \\
\text { l internationally, not even organized } \\
\text { Is in the business of [Dutch MNE], } \\
\text { global. Decorative is much more }\end{array}$ & \multicolumn{2}{|c|}{$\begin{array}{l}\text { "We are much better organized in terms of having country managers } \\
\text { and functional structures, which are much more European-based. So } \\
\text { in terms of R\&D, although we have some labs such as that in France } \\
\text { and in Poland, our activities are all pretty well managed in terms of } \\
\text { knowing what is going on and who is doing what... There are [links], } \\
\text { whether they are solid or not, I would not like to say, some are solid } \\
\text { some are dotted lines, but there is a lot of clarity". }\end{array}$} \\
\hline $\begin{array}{l}\text { Participation } \\
\text { patterns (i.e. the } \\
\text { extent to which } \\
\text { and diversity of } \\
\text { CoPs that engage } \\
\text { in new practices) }\end{array}$ & $\begin{array}{l}\text { Scale and scope } \\
\text { of interaction }\end{array}$ & $\begin{array}{l}\text { "A bit comes from the leader- } \\
\text { level in filling and in production, } \\
\text { but for the most part it comes } \\
\text { from the people working on the } \\
\text { machines day-in day out and say: } \\
\text { 'Listen, I have a problem here } \\
\text { can't we do this or that'.” } \\
\text { "A wall between different } \\
\text { departments" } \\
\text { (operator)..."internalized the } \\
\text { interface” between maintenance } \\
\text { and production" }\end{array}$ & $\begin{array}{l}\text { "Many of the suggestions made by } \\
\text { [an external consultancy firm] had } \\
\text { already been made by other operators } \\
\text {... but had not been acted on by } \\
\text { management". } \\
\text { "There should be more regular } \\
\text { briefings and more investment in } \\
\text { management training...At first, the } \\
\text { push from above is big, but then it } \\
\text { withers over time because people are } \\
\text { busy." }\end{array}$ & $\begin{array}{l}\text { "We set up a culture for people } \\
\text { to ask for help. We were used } \\
\text { to saying, 'we will fix it for } \\
\text { you'. With the changes, people } \\
\text { are encouraged to fix their own } \\
\text { problems. If they make a } \\
\text { wrong decision, they are not } \\
\text { penalized." (managing } \\
\text { director) }\end{array}$ & $\begin{array}{l}\text { "They are probably the best of } \\
\text { the operators we have got. } \\
\text { Given the nature of the job, we } \\
\text { have actually asked volunteers } \\
\text { and we have got the best } \\
\text { trainers. Those who actually } \\
\text { train the guys in the factory } \\
\text { volunteered". } \\
\text { Observation: The operators } \\
\text { chaired 'toolbox meetings' and } \\
\text { challenged the management } \\
\text { team to put in place } \\
\text { technicalities that would } \\
\text { improve operations and have }\end{array}$ \\
\hline
\end{tabular}




$\begin{array}{lll}\begin{array}{l}\text { Learning } \\ \text { outcome (i.e. the } \\ \text { extent to which } \\ \text { subsidiary }\end{array} & \begin{array}{l}\text { Sustenance/Non } \\ \text { sustenance of }\end{array} & \begin{array}{l}\text { "There is a manager who really } \\ \text { workderstands how to do }\end{array} \\ \begin{array}{l}\text { workforce } \\ \text { integrates new }\end{array} & \begin{array}{l}\text { this...much better than I do. If } \\ \text { you want to get this continuous } \\ \text { practices) }\end{array} & \begin{array}{l}\text { improvement in place, you have } \\ \text { to change your style from being } \\ \text { extremely directive to a } \\ \text { completely different way of } \\ \text { managing". }\end{array}\end{array}$

"If I had [to rate the extent to which the principles had been taken on board on] a scale from 1 to 10 , then I would say we are on 1 out of 10 ".

"The PIGs died before they started".
"Our operational initiatives focus on bottom-up changes in ways of working. Without openness and transparency, we know that we cannot enable and sustain change". "We were told to do it and we did it". them commit to a deadline.

"These guys almost memorized the number of every valve in that plant and what it did and where does it lead to and what would happen in an emergency situation."

Documentary evidence:

Reduction in unit costs from $10.4 \mathrm{p} / \mathrm{L}$ in 1998 to $7.7 \mathrm{p} / \mathrm{L}$ in 2002 